\title{
ASPECTOS GERAIS DO MESSIANISMO
}

\author{
Maria Isaura Pereira de Queiroz \\ (Universidade de São Paulo)
}

Em trabalho recente 1 examina Vittorio Lanternari a ocorrência atual de diversos movimentos de revivalismo religioso ligados à libertação de povos nativos, avultando pela freqüência e importância os de tipo messiânico. Todos êstes cultos determinados pela reação contra o branco - formação de sociedades secretas, de cultos de fetiches, de seitas em que o transe místico é o fulcro das atividades - são englobados numa mesma categoria sob a denominação de "cultos proféticos de libertação". Acha o autor que, se existem diferenças de condições históricas e culturais entre tais movimentos, estão também ligados entre si por um nexo indissolúvel: decorrem das condições de crise em que se encontra hoje em dia a sociedade colonial.

Os frêmitos de revolta que sacodem várias partes da África e da Oceânia em sua raiz não são mais do que tentativas de renovação religiosa antecedendo forçosamente revoltas políticas e militares contra o branco invasor e dominante. Representando o produto espontâneo do choque entre a cultura hegemônica e as culturas aborigenes, são, no entanto, "estranhos a qualquer propaganda ou jôgo político das grandes potências modernas" 2. Exprimem a necessidade de renovação da cultura nativa quando posta em contacto com a civilização branca ocidental; mas também se vinculam profundamente às tradições religiosas indígenas e, através delas, às diferentes experiências existenciais aborigenes, embora sofrendo transformações, revisões, redefinições determinadas pela própria sobrevivência dêsses aspectos culturais ${ }^{3}$. E', pois, evidente o dinamismo interior das culturas primitivas, contrariando a pretensa qualificação de estáticas que tantas vêzes lhes foi atribuída 4 .

A utilização da religião para veículo de reivindicações resulta da função profana que possui tanto nas culturas nativas quanto nas populares: está voltada para a resolução de crises existenciais concretas determinadas pela dinâmica histórica e desempenha o seu papel por intermédio da instauração de formas adequadas de resgate mítico-ritual.

$\mathrm{Na}$ África, é sobretudo a partir de 1921 que o aparecimento de tais cultos se intensifica, desde as pregações de Simão Kimbangu. A história ciêste líder é típica. Educado em missão batista britânica, teve contacto com a cultura européia. Repetidos sonhos e visões desvendam-lhe a vo- 
cação e levam-no a se tornar pregador da nova fé ao seu povo; alcança muito depressa numeroso séqüito de prosélitos que crêem na sua missão, confirmada por curas milagrosas e por ressurreições. Anuncia iminente a libertação dos negros do domínio dos brancos, a renovação das condições de vida, o retôrno dos mortos, o advento da Idade de Ouro. Perseguido, fugitivo, entrega-se voluntàriamente para sofrer como sofrera Cristo, morrendo no cárcere em 1950. Sua ação, favorecendo por um lado uma atmosfera cada vez mais hostil aos brancos, por outro promove a fundação de uma "igreja nativa". Prisão e sofrimento elevam-no aos olhos do povo ao nivel de fundador e mártir de uma religião diretamente revelada por Deus aos negros, sem ação intermediária de sacerdotes brancos.

O kimbanguismo é nitidamente ambivalente; de um lado, é produto de reações polêmicas a uma política de forçada assimilação religiosa derivada da propaganda missionária e, de outro, representa o veículo de aceitação, por parte dos nativos, de elementos cristãos. Conhecedor da cultura branca, sente o nativo necessidade de profunda renovação cultural, mas o caminho deve ser procurado por êle próprio, fora da imposição dos brancos e contra ela. Teve o líder sucessores e copiadores em tôda a região do Congo: André Matsúa, Simão Mpadi, Mavonda Ntangu e outros mais.

Todavia, em Angola, Kenya, Nyassa, Uganda, outras formas de cultos de libertação apareciam. E na África do Sul, o fenômeno tomou o aspecto da formação de "igrejas separatistas", a partir do protestantismo, proclamando que "a África deve ser dos africanos". Do mesmo tipo são os cultos que apareceram entre os índios norte-americanos em fins do século XIX, Ghost Dance Religion e o culto do peiote. Na América do Sul, ocorreram desde o início da colonização, particularmente entre os índios guaraní. Na Polinésia, propiciaram no século passado a reação contra inglêses e franceses e a um primeiro tempo de luta seguiu-se a organização de uma "igreja" sincrética e nativista, buscando equilíbrio entre os valores tradicionais e o cristianismo. Na Melanésia ainda hoje os indigenas, guiados por messias, abandonam o trabalho e se entregam a grandes cerimônias enquanto esperam o desejado retôrno dos mortos que anuncia a expulsão dos brancos e a distribuição de tôda sorte de riquezas e benefícios. Em Java, tais cultos fomentaram a revolta aberta anti-holandesa, que culminou com a independência em 1949.

Por tôda parte apresentam os movimentos messiânicos os mesmos caracteres: difusão da crença na vinda de um messias libertador, que será anunciado por acontecimentos catastróficos; amálgama entre crenças nativas e crenças cristãs, entre elementos do ritual cristão e do ritual tradicional, constituindo o meio de alcançar a era em que os brancos serão escravos. A Bíblia, nesta conjuntura, adquire novo simbolismo: no primeiro plano estão todos os trechos que possam ser interpretados no sen- 
tido da libertação, como o mito de Davi e Golias, encarado como símbolo da luta entre pretos e brancos e de conseqüente vitória dos primeiros. Mas também os elementos religiosos tradicionais são utilizados dentro de um novo quadro de referências: associam-se à função de expulsão dos brancos que não constava da tradição.

Dois motivos aparecem intimamente ligados: o fim e a regeneração do mundo - a expulsão ou o extermínio dos brancos, sendo o primeiro condição para a segundo. Estão na base de todos os cultos proféticos de libertação e exprimem o desejo de uma era de liberdade e bem-estar, em contraposição ao estudo atual de opressão e de miséria. Os acontecimentos catastróficos significam as reviravoltas da ordem atual, comandadas pelo messias, cujas ordens são fielmente cumpridas pelos adeptos e resultarão na vinda da Idade de Ouro. A esperança no renascimento cósmico atira o grupo para o fim do mundo; êle sai ritualmente da história - o que é concretizado pela cessação das atividades econômicas habituais numa atmosfera de grande exaltação religiosa.

Acha Lanternari que tais movimentos são semelhantes aos observados na antiga cultura israelita. O mosaísmo resultou do choque entre uma civilização pastoril fundada no culto do Ser Supremo e a dos povos agrícolas e sedentários politeístas entre os quais tentava se implantar. $\mathrm{Na}$ época do exílio assírio, que ameaçava pela própria raiz a existência do povo hebraico, surge o messianismo biblico. Procuravam ambos, como os movimentos nativistas atuais, a salvação na luta.

Nestas formações há a considerar duas fases: a da ação imediata e de combate visando à independência (como o kimbanguismo, a Ghost Dance Religion, os movimentos da Polinésia), e uma fase seguinte em que é elaborada religião salvadora de tipo contemplativo e organizatório-eclesiástica (como o culto "bwiti", as igrejas nativas africanas, o peiotismo norte-americano, o ringatu entre os maori).

Os movimentos messiânicos não são, porém, causados sòmente pelo desejo de libertação dos povos nativos. Aparecem também em sociedades primitivas anteriormente ao contacto com o europeu, e no mundo ocidental moderno. Ao contrário das manifestações que examinamos até agora, em que o fator predominante - o choque cultural - é externo, são aquelas endógenas, seus fatôres são de ordem interna. Nesta categoria classifica movimentos brasileiros como os de Canudos, Contestado e Juazeiro, assim como a busca da Terra sem Males, das tribos guaraní.

O exemplo típico, porém, é o próprio cristianismo, que nasceu num momento de tensão aguda entre o sacerdotalismo e as necessidades religiosas do povo judeu; a ação eclesiástica imposta pelas camadas superiores se chocava com exigências religiosas populares, radicadas de modo imediato e espontâneo nas formas de existência coletiva, e que não eram atendidas. Em seguida, em Roma, passa o cristianismo a exprimir a luta 
entre o estatalismo e o individualismo. Surge sempre, então, como manifestação popular oposta a fôrças hegemônicas opressivas. Contra estas, só era possivel uma reação: condenação global dos valores da existência social vigente, considerando-se como positivos apenas os da existência extraterrena; o advento de um reino transcendente anulará a estrutura social em causa.

Esta é a grande diferença entre os dois tipos de movimentos. Seja qual fôr o nivel cultural em que se processem - nativo ou ocidentalizado -, o movimento endógeno efetua uma evasão radical da sociedade e do mundo; funda num plano de extra-historicidade sociedade e mundo próprios, eximindo-se de qualquer ação modificadora direta e combatente contra o exterior. Só é levado à luta quando a sociedade mais ampla, à qual se tornou exterior em virtude do isolamento em que se colocou, se disponha a atacá-lo. Então é que realiza o caráter peculiar dos movimentos de origem externa, cujo aspecto mais importante é o da luta contra as potências hegemônicas para aniquilá-las. Proclamam assim os movimentos endógenos a renúncia aos valores imediatos e imanentes, negam os valores terrenos e buscam refúgio no mundo sobrenatural; ao contrário dos movimentos de origem exterior, que os valores imediatos dominam com seu grande pêso.

No entanto, se é preciso distinguir entre movimentos de origem externa e movimentos de origem endógena, cumpre lembrar que no desenrolar do processo concreto consttiuem antes dois momentos intimamente concatenados entre si. Não há movimento profético de origem externa em que não exista crise de ordem interna; e reciprocamente, nenhuma formação profética de origem interna deixa de ter repercussões importantes nas relações exteriores do grupo. Qualquer choque exterior tanto gera a crise quanto coloca a sociedade, internamente, na alternativa de seguir uma via tradicional já superada pelos fatos ou uma nova via em elaboração no próprio seio da respectiva cultura. Nos movimentos de origem endógena, por sua vez, são recolocadas na pauta as relações do grupo com a sociedade circundante, de que se separa e à qual, portanto, se torna exterior.

Todos os cultos proféticos de libertação, tanto os de origem exterior quanto os de origem endógena, têm como autênticos precedentes históricos os movimentos proféticos e messiânicos de que foi protagonista a civilização religiosa ocidental. Os povos nativos percorrem hoje, devido ao choque súbito com a cultura branca, um itinerário religioso que a cultura ocidental em seu tempo percorreu, no ato de sua fundação e em seus primeiros estágios.

$$
\text { *** * }
$$

Resumidas assim as observações de Lanternari, é interessante cotejálas com os dados que utilizou na marcha de seu raciocínio. Afirma partir de uma abordagem dialético-histórica, isto é, procura descobrir os pro- 
cessos que, por sua ação e reação, històricamente levaram ao desenvolvimento dos cultos. E contrapõe esta abordagem a uma outra, estático-morfológica que encontraria os fatôres principais na própria estrutura interna dos respectivos grupos.

Esta posição leva-o a considerar que, nos cultos de libertação, depois de uma fase de ação imediata e de luta, segue-se muitas vêzes a elaboração de uma religião salvadora de tipo organizatório-eclesiástico e contemplativo. Na África, os movimentos ba-kongo seriam o primeiro momento, o culto "bwiti" e as "igrejas separatistas" o segundo. Na América do Norte, a Ghost Dance Religion seria o primeiro momento, o culto do peiote o segundo.

No entanto, a cronologia do aparecimento de tais cultos não é respeitada. Em 1902, Maurice Leenhardt chamava a atenção para as "igrejas separatistas", que existiam desde os fins do século XIX, advertindo que se desenvolviam no sentido de reivindicações sócio-políticas ${ }^{5}$. O culto "bwiti" se dissemina no Gabon a partir de $1900^{6}$. Ora, o kimbanguismo se origina em 1921 - não há a relação de precedência apontada.

Culto "bwiti", kimbanguismo, "igrejas separatistas" passam-se outrossim entre povos geogràficamente separados e culturalmente diferentes. Os ba-kongo (kimbanguismo) habitam o Congo Belga, o Congo Francês, parte de Angola; os fang (culto "bwiti"), pertencem ao Camerum, à Guiné Espanhola, ao Gabon; as "igrejas separatistas" existem na África do Sul. Ora, a África não é uma só, é imensa colcha de retalhos cie culturas as mais diversas, não havendo nela a unidade sócio-cultural implícita nos raciocínios de Lanternari. Nessa diversidade está, segundo Balandier, a diferença das reações manifestadas pelas tribos diante da experiência comum de colonização.

$\mathrm{E}$ o que é mais, não só tais cultos não aparecem na sucessão indicada pelo autor, como todos êles coexistem até hoje na África, circunscritos aos diferentes povos em que se originaram e que apontamos atrás.

O culto do peiote, por sua vez, surge contemporâneamente ou mesmo um pouco antes do desenvolvimento da Ghost Dance Religion, cujos primórdios são de 1870 mais ou menos; de novo não há aqui precedência. Todavia, aquelas tribos a principio empenhadas na Ghost Dance Religion, dissolvida esta, adotam o culto do peiote. Bernard Barber, porém, mostra a importância da esperança no primeiro culto: enquanto a Ghost Dance Religion procura reorganizar as condições sócio-culturais insatisfatórias, o culto do peiote reflete subordinação passiva a estas, aceitação resignada de circunstâncias consideradas inamoviveis; ao contrário da Ghost Dance Religion, nada tem de construtivo. Não sendo ameaçador para a cultura branca, persiste, enquanto a Ghost Dance Religion é combatida, reprimida, extinta. 
O culto do peiote não pode, pois, nem mesmo ser caracterizado como culto nativo de libertação, uma vez que não se insurge contra o domínio dos brancos; sua adoção decorre da situação desesperadora das tribos diante de um mundo sócio-cultural literalmente em ruínas e que nenhuma ação - nem mesmo a ação sócio-religiosa da Ghost Dance Religion - conseguia mais salvar ou renovar 7 .

Com relação às "igrejas separatistas", repara Bengt Sundkler que ao nascer são de tipo agressivamente antibranco; isto é, embora não visem nunca à luta armada 8 , sua pregação é deveras ameaçadora. A agressividade tem por fim cimentar a coesão interna do grupo e, bem sucedida a nova seita, o movimento toma forma mais pacífica; continua plenamente antibranco, mas a agressividade se ameniza a fim de que seja possível continuar existindo dentro do mundo colonial 9 .

Não há, pois, o processo apontado por Lanternari no desenvolvimento dos "cultos de libertação", entre um movimento messiânico antecedente e um culto contemplativo conseqüente. O próprio movimento messiânico pode apresentar fases agressivas e pacíficas. Outros existem em que não há senão um aspecto, como o kimbanguismo, que continua tendo hoje os mesmos caracteres que apresentou em seu início. Ou as fases podem estar invertidas: no movimento do Contestado (Brasil), a uma primeira fase inteiramente pacífica segue-se a "guerra santa", proveniente dos ataques do govêrno central contra os jagunços.

Um dos estudos utilizados por Lanternari para base de suas reflexões é o de Georges Balandier, sôbre as reações dos fang e dos ba-kongo à colonização. Colocados em situação comum, "a ação do colonizador, que abre uns e outros às influências exteriores" 10, apresentam movimentos diferentes - o movimento "bwiti" entre os primeiros, o kimbanguismo entre os segundos.

Do ponto de vista do processo, realmente parece não haver que distinguir entre ambos, e as "igrejas separatistas" estudadas por Bengt SundkJer também são semelhantes: tentativas para ultrapassar as conseqüências do choque entre cultura nativa e cultura branca. No entanto, a forma que assumem é suficientemente diferente para constituir a razão de ser de um trabalho como o de Georges Balandier, que parece uma continuação da análise de Bernard Barber; êste, no final de seu artigo colocava a questão: visto que o choque cultural se observa em largas áreas, por que - messianismo se circunscreve a determinados povos? Diante de um fator externo, que é o mesmo em ambos os casos, acha Balandier necessário averiguar "como intervém, em que sentido e em que grau, o fator interno, a estrutura e a organização destas sociedades no que possuem de mais específico" 11.

Nunca dispuseram os Fang de verdadeira hierarquia e sim de um conjunto de precedencias submetidas ao contrôle de todos os membros adultos 
do grupo; entre êles não existia nem mesmo um têrmo pelo qual se pudesse traduzir a palavra "chefe", só havia um único nivel social. Uma liderança efêmera que chegasse a se estabelecer era submetida à mais €streita vigilância. Havia forte sistema de defesas contra a concentração do poder em mãos de um só, e esta sociedade militar conquistadora nunca apresentara nem mesmo os rudimentos mais simples de uma estrutura feudal. O culto "bwiti" congrega todos os que desejem penetrar na seita, submetidos a uma iniciação que permite ao neófito participar, de maneira igual à dos outros adeptos e no mesmo nivel, de uma sabedoria extracrdinária.

Mantinham os ba-kongo, ao contrário, relativa centralização concretizada na pessoa do "chefe coroado", que ocupava o supremo pôsto tribal, com direitos sôbre tôda a terra e autoridade sôbre todos os homens. Os messias que ali surgem, a partir de Simão Kimbangu, têm os mesmos direitos dos antigos chefes tribais; seguem, nas relações com os adeptos, o modêlo do antigo "chefe coroado" tradicional.

A forma que assumem os dois movimentos é, pois, essencialmente diferente. Resta verificar se há influência da estrutura interna do grupo sôbre êles, isto é, verificar a hipótese de Balandier, através do exame de cutros casos.

O mesmo fenômeno foi observado por Bengt Sundkler nas "igrejas separatistas". A sociedade zulú tinha o rei como chefe supremo, "dono da terra e do povo"; realizava as cerimônias religiosas mais importantes, dispunha da maior riqueza, a qual devia ser utilizada para ajudar generosamente sua gente. O líder religioso das diferentes seitas separatistas é como o antigo rei zulú, e a seita constitui a sua tribo. Quanto mais foi a realeza tribal perdendo sua importância, mais o padrão real foi enèrgicamente projetado sôbre o líder religioso, conclui Sundkler 12 .

Esta aliança entre estrutura social centralizada e movimento messiânico não é peculiar apenas aos movimentos decorrentes do choque cultural. Observa-se nos casos brasileiros, por exemplo, que segundo Lanternari são endógenos. Nas tribos guaraní, a posição social mais elevada é a do pajé, médico-feiticeiro, chefe político, autoridade suprema, detendo todos os meios de contrôle sôbre a vida profana e sobrenatural do grupo ${ }^{13}$. Ora, o movimento guaraní repete a estrutura habitual da tribo.

$\mathrm{Na}$ antiga estrutura rústica brasileira, por sua vez, um grande proprietário local podia tornar-se chefe de determinada zona, alta autoridade, orientador político, conselheiro dos subordinados. Trata-se novamente e uma organização social centralizada em tôrno de um chefe total - regioso até. Pois a escassez de padres no Brasil fêz com que não raro os oronéis" se arvorassem em organizadores das cerimônias religiosas; aina quando um padre se instalava em seus domínios, só se mantinha na meda em que lhe acatava o mando. Com relação ao grupo que reúnem à 
sua volta, a solidariedade é principalmente patrimonial; os agregados se prendem ao chefe pelos benefícios recebidos.

Ora, nos movimentos messiânicos, além de o líder reunir tôda a autoridade em suas mãos, não era apenas a crença em seu poder divino que atraía e fixava os romeiros em tôrno dêle, mas também os benefícios que dêle receberam. A ligação era perfeitamente patrimonial: o jagunço se referia sempre ao benefício que recebera do líder para justificar sua adesão, além da crença na essência religiosa daquele ${ }^{14}$.

O exame de casos diferentes confirma, pois, a hipótese de Georges Balandier sôbre a importância do meio social interno e caracteriza também o tipo de influência que êste exerce, tanto sôbre os movimentos de origem exterior quanto sôbre os endógenos. O sofrimento coletivo, tomado isoladamente, pode determinar reações as mais variadas; associado à estrutura centralizada em tôrno de um chefe, orienta-a em determinada direção. A estrutura social interna não pode, pois, ser afastada por quem estuda o messianismo; associa-se a outros fatôres concorrentes, mas designa o modêlo que a reação tomará ao se desenvolver. 'Eis o que verificamos em trabalho anterior, não a partir de uma posição teórica tomada de antemão, e sim depois do exame de casos brasileiros e de casos estrangeiros 15 .

No entanto, a verificação da importância da estrutura não significa que a análise do processo seja posta de lado; quer apenas dizer que, para que exista um processo, é imprescindivel que existam estruturas e que estas estruturas influenciam o processo - o qual, por sua vez, modificará as estruturas. As abordagens pela estrutura e pelo processo não se excluem, completam-se.

As duas ordens de movimentos - os de origem endógena e os de origem exterior - seriam no entanto, segundo Lanternari, essencialmente diferentes. O movimento messiânico de origem exterior tenderia a colocar o caminho da salvação "na ação imediata, na luta, na polêmica direta e decidida contra as instituições estrangeiras...". O de origem endógena ligaria a salvação "à ação religiosa e moral" muito mais "do que à ação política externa", polarizando-se "em tôrno do escaton ou fim do mundo (...) enquanto se proclama a renúncia aos valores imediatos e imanentes de utilidade terrena", justamente aquêles que dominam "com seu grande pêso as movimentos nativistas de nível etnológico"16. Vimos que os movimentos brasileiros são classificados entre os endógenos.

No entanto, êstes visam antes de mais nada à transformação da ordem política local 17. Os messias rústicos não reivindicam uma reforma total da estrutura social vigente (não pedem que a camada dos caboclos tome o lugar da dos "coronéis"; a cultura nativa, ao contrário, pretende o lugar ocupado pela cultura hegemônica). O que desejam é a substituição de determinados chefes locais por outros, a renovação da estrutura política em suma, de que é símbolo o desejo de reinstalação da monarquia. 
Um dos jagunços do Contestado assegurava que lutava pela volta da monarquia, mas só largaria as armas quando o Coronel Chiquinho de Albuquerque fôsse substituído, no poder municipal, pelo coronel Henriquinho de Almeida... 18. Na sedição de Juazeiro, depois de vencido Franco Rabelo, presidente do Ceará, marchariam para Pernambuco, a fim de derrubar Dantas Barreto, e então "nóis grita a Monarquia", afirmava um combatente 19.

$\mathrm{O}$ alvo a atingir é, pois, político - vem se inscrever entre os "valores imediatos e imanentes de utilidade terrena", que Lanternari achara característicos dos movimentos de origem exterior - tenta-se substituir um chefe, que se hostiliza, por outro, que é simpático. Os movimentos estão, assim, orientados para a vida profana.

Realmente, todos os movimentos messiânicos que conhecemos, seja de nivel etnológico, seja passados na civilização ocidental, têm por meta algo de objetivo e prático, decorrente das dificuldades e tensões da vida social e visando a ultrapassá-las; a modificação é alcançada pelo recurso à construção de um novo mundo terreno. Os meios de que se lança mão, de tipo sobrenatural, não só garantem a renovação pretendida, mas tornam transcendente o novo mundo criado. As catástrofes anunciadas são o prenúncio da transformação do mundo profano em mundo sobrenatural; o indivíduo se salva das calamidades ingressando no movimento, o qual o integra num novo mundo ao mesmo tempo religioso e profano, terreno e paradisíaco.

A maioria dos autores que se têm ocupado com o messianismo chama a atenção para esta ambigüidade, para o aspecto ao mesmo tempo histórico e extra-histórico com que aparece aos fiéis. Bernard Barber nota que o messianismo dos índios norte-americanos se refere sempre a uma restauração de valores terrestres, que serão, porém, gozados em ambiente transcendental; nos novos tempos não haverá nem morte nem doenças, só felicidade eterna. O mesmo se pode afirmar dos movimentos indígenas brasileiros.

Nas "igrejas separatistas" da África do Sul, o local onde se instala a nova seita é a realização, nesta terra, do paraíso terrestre. Os líderes religiosos zulú não distinguem sagrado e profano - para êles, o céu é a localidade onde se instala a seita. Nos livros sagrados de Shembe, messias dos mais célebres, Ekuphakameni, sede de sua igreja, é cantada de maneira exultante, sua beleza deslumbrante fortalece a convicção de que realmente é ali o Éden 20 .

E' geralmente difícil a europeus de formação racionalista conceber um mundo terreno que seja ao mesmo tempo sobrenatural, mas esta maneira de pensar está inteiramente conforme à mentalidade dos povos primitivos e à das camadas populares de certos países de civilização ocidental. O próprio Lanternari admitira a princípio a ambigüidade quando assim se exprimira a respeito dos movimentos de origem exterior: "de fato, a inteira 
coletividade (...) entra por assim dizer no fim do mundo, sai ritualmente da história (da ordem), numa atmosfera de exaltação religiosa que, através da cessação de tôda atividade econômica comum e através da espera do renascimento cósmico, realiza a seu modo o mito" 21. Reconhece, pois, que os movimentos de origem exterior também realizam uma "fuga da história", mas não trepida, páginas adiante, em afirmar que para êsses movimentos o aspecto mais importante é o desejo de renovar o mundo profano, enquanto a fuga caracteriza de modo peculiar os movimentos endógenos.

Sob o aspecto da "fuga da história", no entanto, uns e outros são semelhantes, não há que distingui-los, e parecem enquadrar-se na qualidade de "autísticos" que Bernard Baber atribui à Ghost Dance Religion. Não endossamos essa qualificação, pois os indivíduos que se entregam a movimentos messiânicos não buscam no sonho refúgio contra situações sociais adversas. Já o notara Hans Kohn: por tôda a parte, o movimento messiânico é uma fôrça viva e ativa; seus integrantes não se contentam em "esperar", agem para gozar olparaíso aqui mesmo na terra e em plena vida, pondo em prática os meios que o líder indica como capazes de consegui-1o ${ }^{22}$.

Muito mais do que simples reação agressiva contra os brancos, são os movimentos messiânicos tentativas de reorganização social.

James Mooney, contemporâneo da Ghost Dance Religion 'e que a estudou minuciosamente, observa: "Só aquêles que conhecem o ódio mortal que uma vez animara uns contra os outros os Ute, os Cheyenne, os Pawnee, são capazes de apreciar o contraste com o espírito atual de fraternidade mútua, podem compreender o resultado a que chegou a Ghost Dance Religion..."23. Superando dissensões tribais, reestruturava o mundo indigena.

Balandier conclui o mesmo em seus estudos sôbre o messianismo bakongo; êste permite "um reagrupamento que ultrapassa os particularismos e as imbricações que implicam as divisões clânicas e a interdisposição dos grupos clânicos; tenta esta reconstrução de agrupamentos ampliados, na base da adesão voluntária à nova fé..." Dêsse modo, servem para "reintroduzir elementos de organização no seio de sociedades profundamente alteradas" 24 .

O fator externo (choque cultural) passa então para o segundo plano, enquanto o fator interno (reorganização sócio-cultural) constitui realmente a mola mestra dos referidos movimentos. Tanto assim que só há reação quando há desorganização interna do grupo - e, mais ainda, certo grau de desorganização. Se a tribo conserva intacta sua estrutura, não há movimento; noutros casos, êle não aparece porque a desorganização foi de tal ordem que destruiu a esperança nativa - como mostra Bernard Barber. 
No entanto, mais profundamente ainda do que a estrutura tribal, a própria estrutura da personalidade indígena, que se mostra atingida, pode readquirir equilíbrio através do movimento.

A propósito do movimento "jonfrum" nas Novas Hebridas (Melanésia), nota Patrick O' Reilly que não são nem os que conservaram mais ou menos intactos os valores tribais, nem os nativos convertidos ferventemente ao protestantismo os atingidos, e sim os "haf haf", isto é, os que tinham experimentado o regime das missões sem abandonar completamente seu comportamento pagão 25 .

Kroeber refere que a Ghost Dance Religion não se desenvolveu em nenhuma das tribos da área missionária dos Estados Unidos, isto é, não alcançou nenhuma das tribos cuja desorganização sócio-cultural tivera lugar, mas em que a reorganização se processara também em têrmos do cristianismo 26. Bernard Barber conta como rejeitaram os Navaho a pregação do novo culto, ridicularizando os emissários - mas os valores da vida antiga funcionavam ainda entre êles, não sentiam nenhuma necessidade social de um redentor.

A reorganização se exprime no sincretismo religioso que Lanternari apontou existir nos cultos africanos e que é notada tôdas as vêzes que o movimento resulta do choque cultural. E' visivel, por exemplo, no culto de Smohalla, o primeiro grande profeta da Ghost Dance Religion: no ritual que institui unem-se elementos católicos de mistura com outros tomados a paradas militares, juntamente com aspectos revividos da antiga religião tribal 27.

Este processo de reorganização é o mais importante no que tange os movimentos messiânicos. Ele indica novamente que os fatôres de ordem interna são os que mais pesam na determinação dêles, mesmo quando resultam do choque cultural. Com relação a êste aspecto, não há também que distinguir, portanto, entre movimentos de origem exterior e de origem endógena.

Resumindo, podemos concluir:

1. Os cultos proféticos de libertação não constituem mero combate aos brancos e tentativa de se libertar de sua hegemonia; seu caráter mais profundo está na reorganização do mundo nativo que procura efetuar, recrganização que vai dos aspectos sócio-culturais aos de reajustamento da personalidade.

2. Os movimentos messiânicos, que podem se incluir entre os cultos proféticos de libertação, constituem todavia uma categoria mais ampla do que êstes, uma vez que podem ser produzidos exclusivamente por condições internas da cultura em causa, sem nenhuma interferência do choque cultural. Ligam-se aos cultos proféticos de libertação porque procuram a 
reorganização do mundo nativo; mas separam-se dêles porque são arma utilizada por outras culturas, além das atingidas pelo choque cultural, inclusive a ocidental, para renovação ou reajustamento de determinados aspectos seus internos 27 .

3. Além desta maior amplitude dos movimentos messiânicos com relação aos "cultos de libertação" em geral, são também de forma diferente dêstes e agem diferentemente em relação à cultura hegemônica. A forma do movimento messiânico está hoje perfeitamente descrita em numerosos estudos, é reconhecível e inconfundivel, e o próprio Lanternari a caracteriza; não a utiliza, porém, em relação aos outros "cultos de libertação", igualando-os indevidamente. A forma, como vimos, apresenta parentesco com a estrutura interna do grupo em que o movimento tem lugar; isto é, há razão para supor que os movimentos messiânicos se ligam a determinados tipos de estrutura social.

4. Dentro dos movimentos messiânicos, não há razão para distinguir movimentos endógenos e movimentos de origem exterior. A importância ảos fatôres endógenos é a mesma em ambos, e ambos constituem tentativas para superar a contradição interna criada pelo choque cultural ou por tensões próprias à cultura. A distinção prêsa aos objetivos desejados pelos dois tipos de movimento também vimos não se sustentar: ambos promovem a ida para um Paraíso Terrestre que simbòlicamente designa o desejo de uma nova organização sócio-cultural ou de uma renovação sócio-política. Quanto às fases que atravessam, não apresentam nenhuma unidade para permitir que delas provenha também qualquer diferenciação.

De que se conclui, por fim, que não há razão para se opor uma abordagem dialético-histórica a uma abordagem estático-morfológica: mostramos a importância da estrutura social para o processo messiânico, mas não pudemos deixar de encarar como se desenvolve e de que maneira vai agir sôbre a mesma estrutura - isto é, o aspecto reorganizatório que assume. Não é, pois, adotando uma posição teórica a priori que se chega a uma visão clara do objeto de estudo. Os aspectos que êste apresenta é que nos podem inclinar a preferir uma ou outra abordagem, conforme o que se deseja esclarecer - abordagens que não se opõem, mas se completam, quando respeitados os dados que estudam.

\section{NOTAS}

1) Vittorio Lanternari, Fermenti religiosi e profezie di libertà fra i popoli coloniali, Nuovi Argomenti, n. 37, março-abril de 1959, Turim.

2) Id., 1. c., pág. 54.

3) Em excelente artigo, Jacqueline Eberhardt analisa êste aspecto do problema em algumas "igrejas separatistas" da África do Sul: Messianisme 
en Afrique du Sud, Archives de Sociologie des Religions, n. ${ }^{\circ} 4$, julho-dezembro de 1957, Paris.

4) Robert Lowie também já estudara êste aspecto: Le messianisme primitif: contribution à un problème d'Ethnologie, Diogène, n. $.^{\circ} 19,1957$, Paris.

5) Maurice Leenhardt, Le Mouvement Ethiopien au Sud de l'Afrique (1896-1899), Cahors, 1902.

6) Georges Balandier, Sociologie Actuelle de l'Afrique Noire, Presses Universitaires de France, Paris, 1955.

7) Bernard Barber, Acculturation and messianic movements, American Sociological Review, vol. VI, n.o $5,1941$.

8) Os movimentos messiânicos de que temos conhecimento se apresentam como pacíficos; a luta armada é sempre pruvocada pela cultura hegemônica ou pela sociedade circundante. Bernard Barber repara que a Ghost Dance Religion era de paz; a revolta dos Sioux resulta de evidente provocação branca, - o que afirma James Mooney, contemporâneo dela. G. Balandier fala do caráter pacífico do kimbanguismo, e Bengt Sundkler, do das "igrejas separatistas". A mesma peculiaridade têm os movimentos brasileiros, que'só combatem para se defender do poder central.

9) Bengt Sundkler, Bantu Prophets in South Africa, Lutterworth Press, Londres, 1948, págs. 106-107, 116.

10) Georges Balandier, 1. c., pág. IX.

11) Id., 1. c., pág. IX. O grifo é do texto.

12) Bengt Sundkler, 1. c., pág. 106.

13) Egon Schaden, A Mitologia Heróica de Tribos Indígenas do Brasil, Serviço de Documentação, Ministério de Educação e Cultura, Rio de Janeiro, 1959, pág. 118.

14) Maria Isaura Pereira de Queiroz, La "Guerre Sainte" au Brésil: Le Mouvement Messianique du Contestado, Faculdade de Filosofia da U. S. P. Boletim n.0 187, São Paulo, 1957, pág. 229.

15) Id., L'influence du milieu social interne sur les mouvements messianiques brésiliens, Archives de Sociologie des Religions, janeiro-junho de 1958 , n. ${ }^{\circ} 5$.

16) V. Lanternari, l. c., pág. 85.

17) J. O. Pinto Soares, A questão dos limites entre Paraná e Santa Catarina, Rio de Janeiro, 1930, pág. 86; Demerval Peixoto, A Campanha do Contestado, Rio de Janeiro, 1920, págs. 229-230.

18) A Tribuna, Curitiba, Paraná, 2 de fevereiro de 1914. São Paulo.

19) Lourenço Filho, Juazeiro do Pe. Cícero, Cia. Melhoramentos de

20) Bengt Sundkler 1. c., págs. 213, 292, 294.

21) V. Lanternari, 1. c., pág. 59.

22) Hans Kohn, Messianism, Encyclopedia of the Social Sciences.

23) James Mooney, The Ghost Dance Religion and the Sioux outbreak of 1890, Bureau of American Ethnology, XVI Annual Report, Smithsonian Institution, 1892-1893, Part 2, Washington, 1896. 
24) G. Balandier, 1. c., págs. 426, 449.

25) Patrick O’ Reilly, Prophétisme aux Nouvelles Hébrides, Le Monde non-chretien, Nouvelle Série, abril-junho de 1949, Paris, n. 10.

26) A. L. Kroeber, Handbook of the Indians of California, Bureau of American Ethnology, Bulletin 78, 1925, Washington.

27) Neste ponto discordamos outra vez de Lanternari, quando afirma que os movimentos messiânicos são todos herdeiros daquêle que se iniciou na religião judaico-cristã, e que as culturas nativas, sob o impacto da cultura branca, percorrem 'hoje "um itinerário religioso que a cultura ocidental percorreu em seu tempo" (pág. 62). O fato de tais movimentos existirem em culturas nativas que não experimentaram choques com os brancos invalida tal hipótese, recolocando a questão nos têrmos vistos por Wilson $\mathrm{D}$. Wallis, isto é, de que "não constituem (os movimentos messiânicos) posse exclusiva", da corrente judaico-cristã, mas "pertencem antes à humanidade", constituindo "uma fase 'da vida humana que encontra paralelismo em regiões do gíobo extremamente separadas e não relacionadas històricamente" (Messiahs, Christian and Pagan, Richard G. Badger, Boston, pág. 9). O paralelismo entre o movimento e determinados tipos de estrutura social concorre para fortalecer êste ponto de vista. 